\title{
Based-Carbon Reinforcements for Aluminum Composites
}

\author{
R. Pérez-Bustamante ${ }^{1}$, D.C. Acosta-Peña ${ }^{2}$, A. Reyna-Cruz, E. Lopez-Contreras ${ }^{2}$, R. Vazquez-Marquez ${ }^{2}$ \\ F. Pérez-Bustamante ${ }^{1,2}$, M.Miki-Yoshida ${ }^{1}$, J.M. Herrera-Ramírez ${ }^{1}$, and R. Martínez-Sánchez ${ }^{1}$ \\ ${ }^{1 .}$ Centro de Investigación en Materiales Avanzados (CIMAV), Miguel de Cervantes No. 120, C.P. \\ 31109, Chihuahua, Chihuahua, México \\ 2. Universidad Autónoma de Chihuahua (UACH), Av. Escorza No. 900. Zona Centro. C.P. 31000, \\ Chihuahua, Chihuahua, México
}

Based-carbon reinforcements (BCR) are interesting materials capable to be applied in several fields in materials science. Because of their excellent chemical, physical and mechanical properties, they are widely applied in electronic, automotive and aircraft industry. In the field of composites, BCR offer the possibility of increasing the mechanical performance of novel materials produced by a wide variety of techniques. However their application shows a dependence of the amount of material produced at reasonable prices. Even though, mechanical properties of nano reinforcements based on carbon, such as nanotubes and graphenes are being found to be with a notorious mechanical behavior over other allotropic carbon forms, the production micrometric reinforcements such carbon fiber and graphite can be carried out in bulk production, in comparison with nanometric carbon reinforcements. However, the mechanical performance of metal matrix composites reinforced with nanometric BCR particles has been shown an steadily increase interest by the scientific community, and numerous studies of nanometric BCR particles such nanotubes [1], graphite nanoparticles [2], and recently the use of graphenes [3] have been published in the field of polymer- and metal-based composites, reporting a positive effect in the final mechanical properties of the produced composites when they are homogeneously dispersed in the matrix [4].

Thus, it is important to study the mechanical and microstructural behavior of several BCR in the production of composites. For this purpose, in this work, carbon nanotubes (CNTs), graphene nanoplatelets (GNPs), carbon fiber (CF) and graphite powder (GP) were used as reinforcement in the production of aluminum composites. The dispersion of BCR was carried out by milling in a high-energy Spex 8000M device. Employed milling time was set to $5 \mathrm{~h}$. Particles reinforcements were added in 1.0 wt.\% concentration in an A17075 matrix. All runs were performed under an argon atmosphere. Methanol was added as process control agent in order to avoid the excessive agglomeration of particles. Powders were cold consolidated under $850 \mathrm{MPA}$ of pressure. Consolidated samples were sintered at $500{ }^{\circ} \mathrm{C}$, under argon atmosphere during $2 \mathrm{~h}$.

Raw materials were characterized by Raman spectroscopy and scanning electron microscopy (SEM), whilst composites were microstructurally characterized by means of X-ray diffraction (XRD), Raman spectroscopy and scanning electron microscopy (SEM). The mechanical behavior of the composites was evaluated in the as-milled and sintering condition through Vickers microhardness with test with $500 \mathrm{~g}$ of load and a dwell time of $15 \mathrm{~s}$. As reference, an unreinforced Al7075 aluminum alloy was produced according to the previous synthesis conditions.

Fig. 1 shows secondary electron SEM micrographs of the morphology of the four BCR particles used in the production of BCR/A17075 composites. It is shown in Fig. 1a CNTs with a diameter in the range of 20-60 nm, whilst Fig. 1b displays GNPs where are presented regions of few graphene layers. Fig. 1c 
shows carbon fibers with a diameter of about $10 \mu \mathrm{m}$. It can be noted a that $\mathrm{CF}$ are exceed 100 times the diameter of the CNTs, in the same way, Fig. 1d show natural graphite flakes with an area superior to 100 $\mu \mathrm{m}$.

Fig. 2 shows the results from Vickers microhardness test in the as-milled and sintering condition. Milled samples show high values compared with the as-milled condition for the Al7075 and its composites due to the hard working produced by the milling process. A fall in the hardness values is obtained with the sintering condition because recrystallization occurred during the sintering process. In both conditions, an increase in hardness is presented in GP/A17075 composites over those reinforced with CNTs and GNPs. In this concern, even though, a harder surface is obtained in composites reinforced with GP, a deeper study about the mechanical behavior in BCR/A17075 composites after compressive test is being carried out.

\section{References}

[1] A. Javadi, S. et, al, Fullerenes Nanotubes Carbon Nanostruct., 21 (2013) p. 436-447.

[2] I. Estrada-Guel, et al, J. Alloys Compd., 536, Supplement 1 (2012) p. S175-S179.

[3] S.F. Bartolucci, et al, Mater. Sci. Eng., A, 528 (2011) p. 7933-7937.

[4] R. Pérez-Bustamante, et al, Powder Technol., 212 (2011) p. 390-396.

[5] Thanks to P. Piza-Ruíz and W. Antúnez-Flores for their technical assistance.
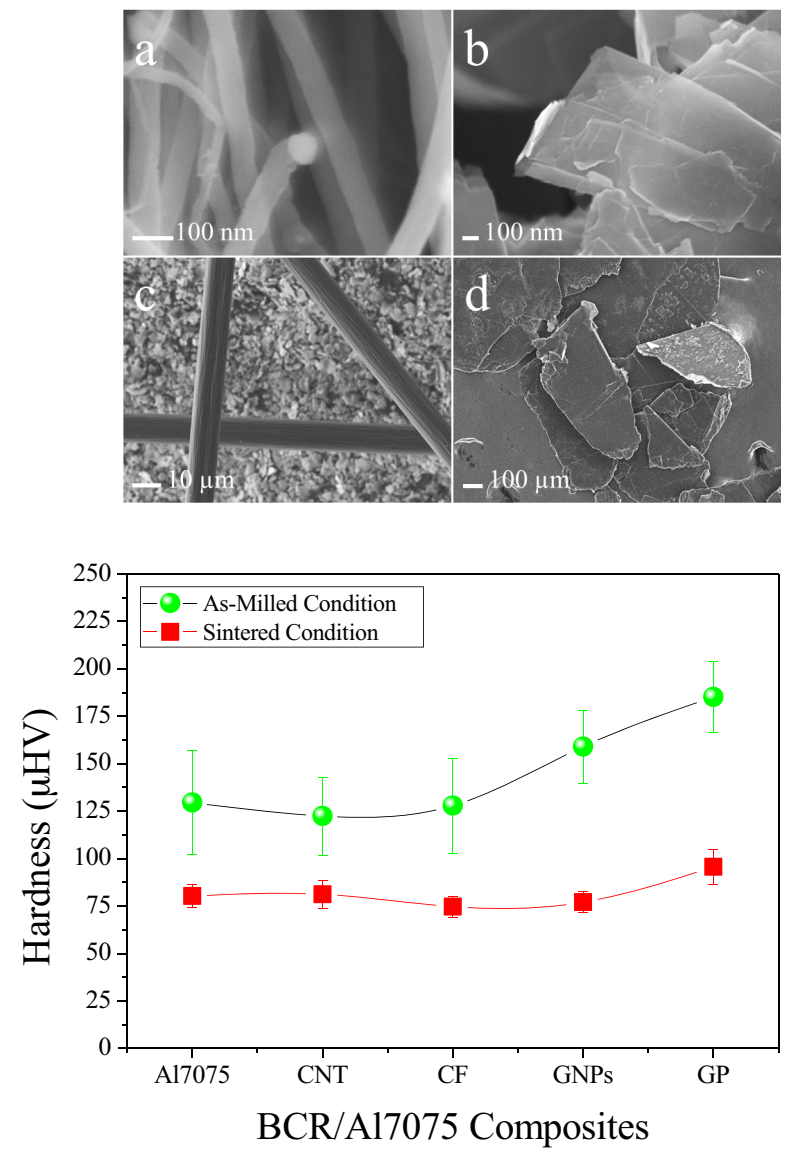

Figure 1. Secondary electron SEM micrographs. (a) Carbon nanotubes, (b) Graphene nanoplatelets, (c) Carbon fibers and (d). Graphite powder
Figure 2. Vickers micro hardness results in the asmilled and sintering condition for BCR/A17075 composites. As reference it is shown A17075 measurements. 